\title{
Thermal performance of sintered miniature heat pipes
}

\author{
Y.-M. Chen, S.-C. Wu, C.-I. Chu
}

Abstract Investigation has been carried out on the thermal performance of sintered miniature heat pipes with $3 \mathrm{~mm}$ outer diameter. In the theoretical analysis, the influence of wick structure parameters is determined by using the theory of capillary limitation. As a result, the degree of importance is found to be as follows: porosity, powder diameter and thickness of wick structure. In the experiments, heat pipes with sintered dendritic copper powder wicks were fabricated and tested. The maximum heat transfer rate is about $13 \mathrm{~W}$ with an effective heat pipe length of $20 \mathrm{~cm}$. By adopting the formulae developed for both sintered spherical powder and fiber and adjusting their proportion, the agreement between experimental results and prediction is found to be quite good in the tested operation temperature range.

\begin{tabular}{ll}
\multicolumn{2}{l}{ List of symbols } \\
$A$ & area \\
$C$ & constant \\
$d$ & diameter \\
$k$ & thermal conductivity \\
$L$ & length (m) \\
$p$ & pressure \\
$Q, q$ & heat transfer rate \\
$R$ & thermal resistance \\
$\operatorname{Re}$ & Reynolds number \\
$\mu$ & absolute viscosity \\
$r_{\mathrm{h}, \mathrm{v}}$ & hydraulic radius of vapor flow pass \\
$r_{\mathrm{s}}$ & pore radius \\
$T_{v}$ & vapor temperature \\
$\psi$ & angle \\
$\lambda$ & latent heat of vaporization \\
$\varepsilon$ & wick porosity \\
$\rho$ & density \\
$\sigma$ & surface tension
\end{tabular}

Dedicated to Professor Franz Mayinger on the occasion of his 70th birthday

Received on 26 February 2001

Y.-M. Chen ( $₫)$, C.-I. Chu

Department of Mechanical Engineering

National Taiwan University

Taipei, Taiwan 106, ROC

S.-C. $\mathrm{Wu}$

National Defense University

Taoyuan, Taiwan, 325, ROC

$\begin{array}{ll}\text { Subscripts } \\ \text { a } & \text { adiabatic section } \\ \text { c } & \text { condenser } \\ \text { e } & \text { evaporator } \\ \text { eff } & \text { effective } \\ \text { g } & \text { gravity } \\ \text { l } & \text { liquid } \\ \text { v } & \text { vapor } \\ \text { o } & \text { outer } \\ \text { i } & \text { inner } \\ \text { w } & \text { wick }\end{array}$

611

\section{Introduction}

Efficient cooling of electronic components is of vital importance to the successful operation of modern electronic devices. The amount of heat generated in these electronic devices must be dissipated in order to maintain the operating temperature limit. Heat pipes as a cooling strategy have demonstrated to be a promising alternative to traditional cooling schemes and offer the possibility of high local heat transfer rates. As an example, the total heat that generates from the current $\mathrm{CPU}$ and other components in notebook computer can be amounted in excess of $30 \mathrm{~W}$. With this amount of heat, the conventional cooling using fin heat sink and/or fan may not be a feasible solution without compromising the size and weight of notebook computer. Heat pipes with an outer diameter of about 3$4 \mathrm{~mm}$ have been demonstrated to be able to solve the problem in the cooling of notebook computer (Nguyen, 1998).

According to the concept of micro heat pipe proposed by Cotter (1965), a heat pipe with a hydraulic diameter on the order of $10 \mu \mathrm{m}$ is considered to be a micro heat pipe. Traditionally, if the hydraulic diameter of a heat pipe is on the order of $1 \mathrm{~mm}$, it is referred to as a miniature heat pipe. A comprehensive review of micro/miniature heat pipes and their limitations was given by Cao et al. (1993). Detailed descriptions and modeling for micro/miniature heat pipes can also be found from Faghri (1995). Miniature heat pipes have the characteristics of conventional heat pipes and are capable of handling higher heat transfer rate than the micro heat pipes.

There can be found three typical types of wick structures for miniature heat pipes. These include axially grooved, wrapped screen and sintered metal powder. In an experimental study, Huang et al. (2000) conducted performance tests with commercially available miniature heat pipes with different wick structures. They found that the 
heat pipes with sintered powder wicks have the best thermal performance among the three. Although there are some studies about the design and performance test of sintered wick heat pipes, for example Pruzan et al. (1991), they are mostly limited to the discussion of heat pipes with a larger diameter. No systematic investigations have been carried out concerning the parametric study of sintered wick structure for miniature heat pipes. Therefore the present study attempted to investigate the thermal performance of miniature heat pipes with sintered copper limit. This means also that the maximum capillary pressure which heat pipes can achieve must be greater than or equal to the summation of all kinds of pressure drop.

Considering the effect of gravity, the balance equation in heat pipes can be expressed as follows:

$\Delta P_{\mathrm{c}} \geq \Delta P_{1}+\Delta P_{\mathrm{v}}+\Delta P_{\mathrm{g}}$

After some mathematical manipulation, the capillary limitation for heat pipes with sintered spherical powder wick can be expressed as:

$$
q \leq \frac{2 \sigma / 0.41 r_{\mathrm{s}}-\rho_{\mathrm{l}} g d_{\mathrm{v}} \cos \psi \pm \rho_{\mathrm{l}} g L \sin \psi}{\left[37.5(1-\varepsilon)^{2} \mu_{\mathrm{l}} / r_{\mathrm{s}}^{2} \varepsilon^{3} A_{\mathrm{w}} \lambda \rho_{\mathrm{l}}+C\left(f_{\mathrm{v}} \mathrm{Re}_{\mathrm{v}}\right) \mu_{\mathrm{v}} / 2\left(r_{\mathrm{h}, \mathrm{v}}\right)^{2} A_{\mathrm{v}} \rho_{\mathrm{v}} \lambda\right] L_{\mathrm{eff}}}
$$

powder wick structure. Emphasis was put on the study of wick structure. In the theoretical analysis, the influence of wick structure parameters was determined by using the theory of capillary limitation. In the experiments, heat pipes with different sintered copper powder wicks were fabricated and tested. Based on the experimental results, prediction formulae for miniature heat pipes with sintered dendritic power wick were proposed.

\section{Theoretical analyses of the heat transfer limitations}

Theoretical analyses of the heat transfer limitations were firstly carried out for copper-water miniature heat pipes with sintered spherical copper powder wick. The heat pipes have an outer diameter of $3 \mathrm{~mm}$ (tube wall thickness is $0.3 \mathrm{~mm}$ ) and a length of $200 \mathrm{~mm}$. The heat transfer limitations include boiling, viscous, sonic, entrainment and capillary limitations. The predictive relations can be found from Faghri (1995) or Peterson (1994). The calculated heat transfer limitations are illustrated in Fig. 1 as a function of operating temperature, which is also the temperature at the adiabatic section of the heat pipe. As can be seen, the actual heat transfer limit is always the capillary

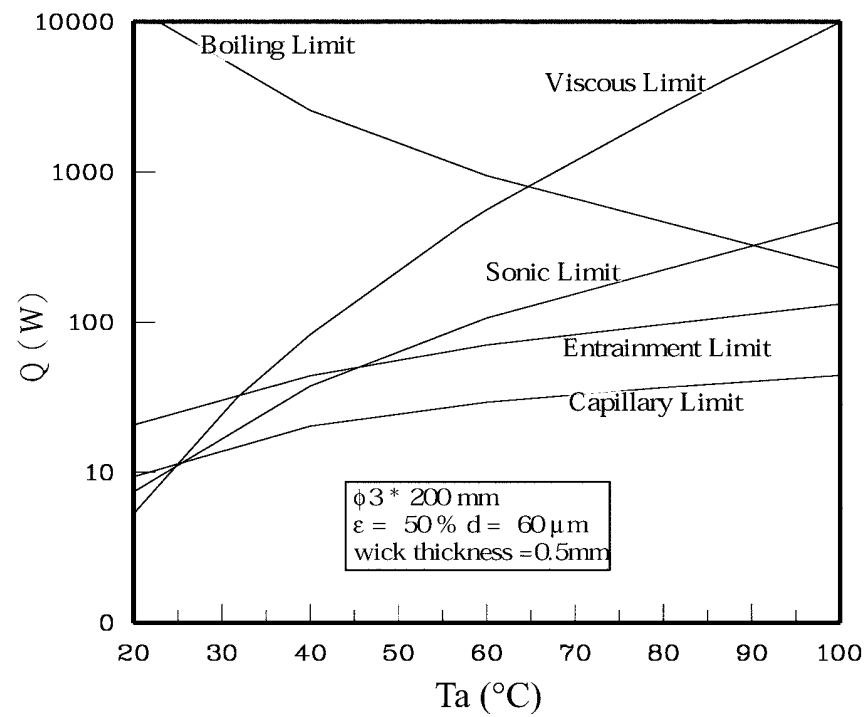

Fig. 1. Heat transfer limitations as a function of operating temperature
Besides the maximum heat transfer rate, thermal resistance is also important in the evaluation of the thermal performance of heat pipes. After an order of magnitude analysis, the total resistance can be written as:

$R=\frac{\ln \left(d_{\mathrm{o}} / d_{\mathrm{i}}\right)}{2 \pi}\left(\frac{1}{L_{\mathrm{e}} k_{\mathrm{p}}}+\frac{1}{L_{\mathrm{c}} k_{\mathrm{p}}}+\frac{1}{L_{\mathrm{e}} k_{\mathrm{eff}}}+\frac{1}{L_{\mathrm{c}} k_{\mathrm{eff}}}\right)$

The variation of the maximum transfer rate with wick thickness is shown in Fig. 2. The powder diameter is the curve parameter. In this example, the porosity is fixed at $50 \%$ and the operating temperature $60{ }^{\circ} \mathrm{C}$. An optimum wick thickness around $0.5 \mathrm{~mm}$ appears for each of the three powder diameters. Optimum values occur due to the influence of wick thickness on both liquid and vapor flows. A larger powder diameter results in an increased maximum heat transfer rate. The thermal resistance increases monotonically with increasing wick thickness.

The effect of porosity on the maximum heat transfer rate is shown in Fig. 3 with the maximum heat transfer rate plotted against powder diameter for two wick thickness. As revealed, porosity has a profound influence on the

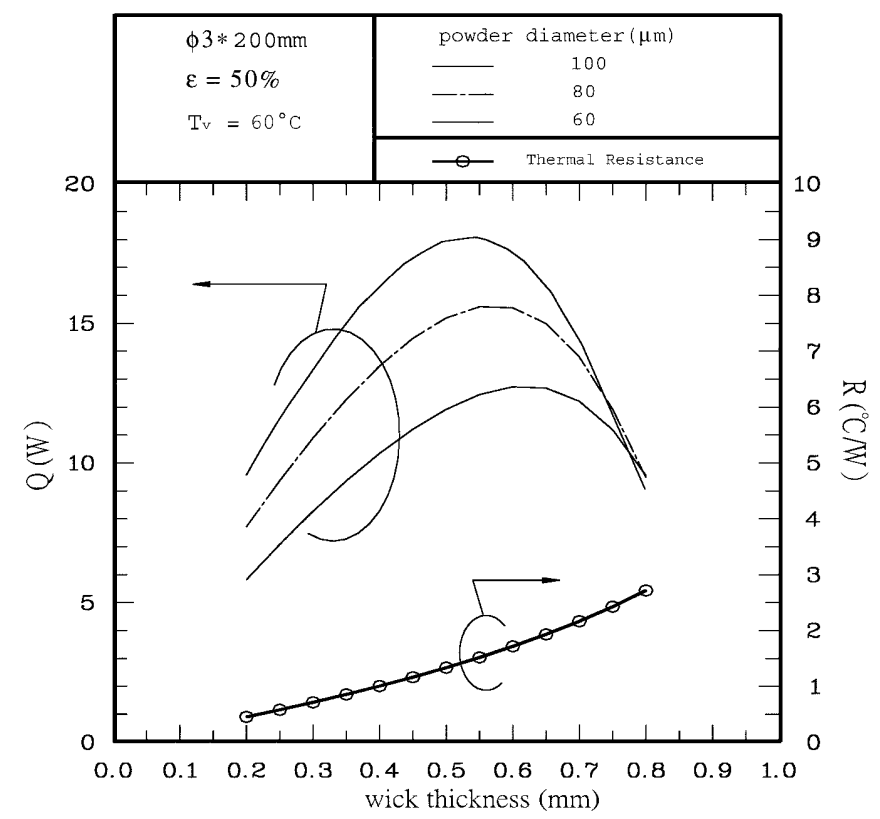

Fig. 2. Effect of wick thickness on the heat transfer rate 


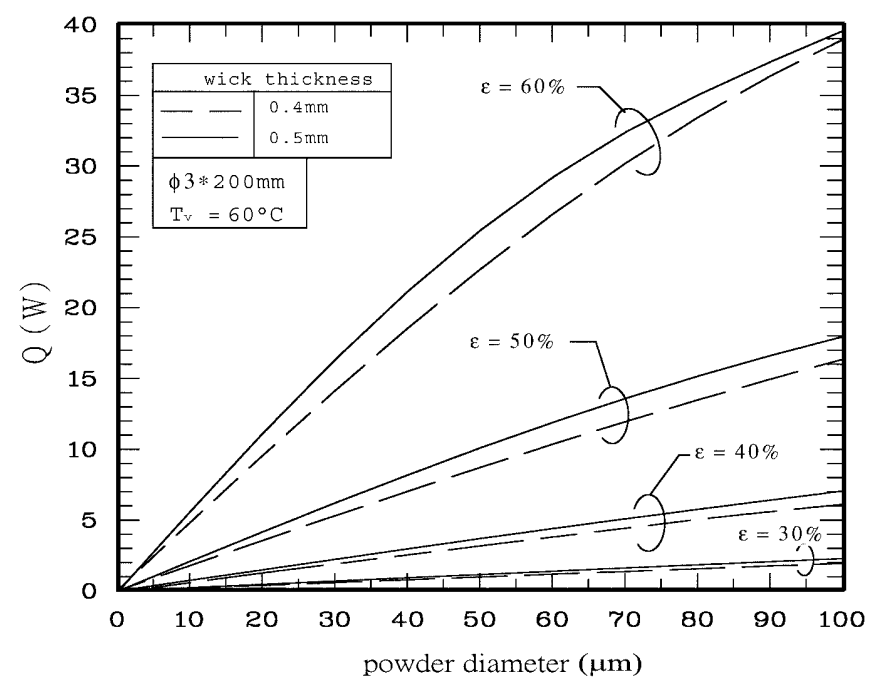

Fig. 3. Effect of porosity on the heat transfer rate

maximum heat transfer rate. A $10 \%$ increase in porosity lead to more than a double increase in the maximum heat transfer rate. This indicates that the liquid flow resistance plays a dominant roll in the maximum heat transfer rate. The maximum transfer rate increases also with increasing powder diameter and wick thickness. As Figs. 2 and 3 show, the degree of importance is found to be as follows: porosity, powder diameter and thickness of wick structure.

Figure 4 displays the variation in the thermal resistance with porosity for different wick thickness. The thermal resistance increases with porosity and wick thickness. This is mainly due to the lower thermal conductivity of water as compared to the copper powder.

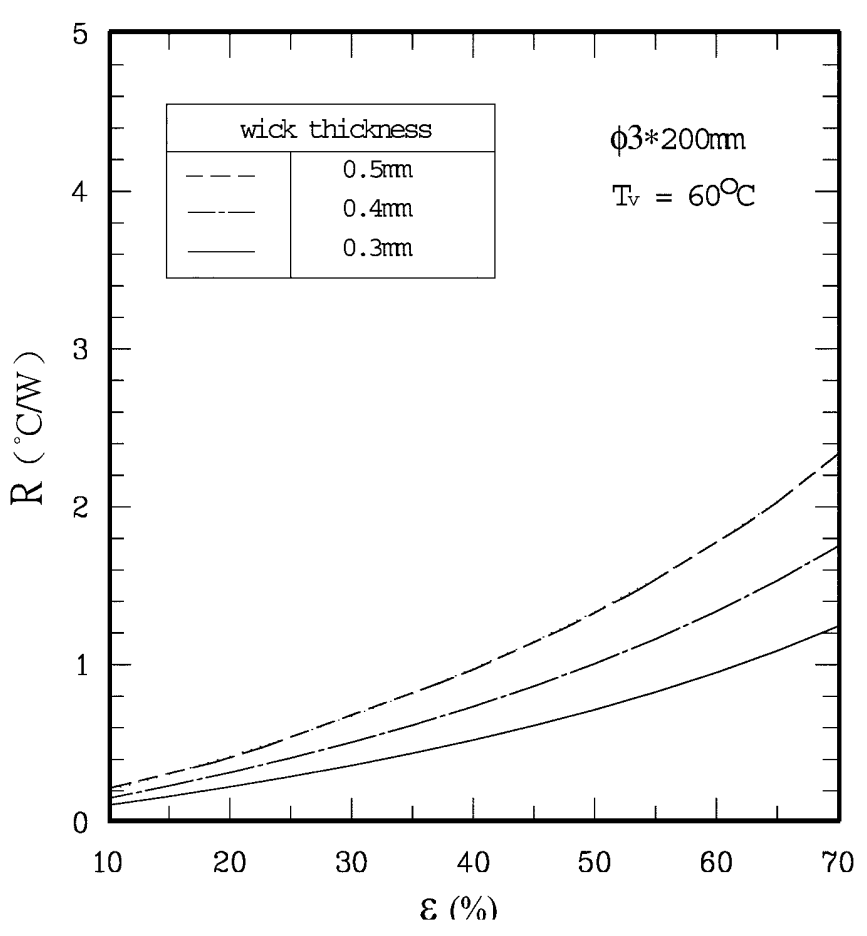

Fig. 4. Effect of porosity on the thermal resistance
2

\section{Experimental set-up and procedure}

Fabrication of the miniature heat pipes

The dimensions of the miniature heat pipes fabricated are listed as below: length of $20 \mathrm{~cm}$, outer diameter of $3 \mathrm{~mm}$, and wick-thickness of $0.5 \mathrm{~mm}$. Since the miniature heat pipes have a very small interior space, filling the copper powder needs a special design. A detailed description about filling procedure and the other fabrication processes can be found from Huang (2000). After the filling process, the copper tubes with copper powder were sintered at $850{ }^{\circ} \mathrm{C}$ for $30 \mathrm{~min}$ in a furnace with a reduction atmosphere. The pore size distribution and porosity of the sintered specimens were determined from measurements with a mercury intrusion porosimetry. Typical pore structures of the sintered wick are shown in Fig. 5 for both spherical and dendritic powder. After the sintering process, the heat pipes were evacuated to a pressure of $1 \times 10^{-4}$ Torr. As the desired vacuum condition was achieved, a small amount of purified water was then injected into the heat pipes. This was done with the help of a well-designed working fluid filling station, in which the evacuation, degassing, and filling with a precise controlled amount were sequentially performed. Over- and undercharging resulted in bed performance or even a malfunction. Finally, pinching the tube and welding their ends sealed the heat pipes.

\section{Measurement apparatus}

A schematic of the experimental set-up for thermal performance tests is shown in Fig. 6. The main apparatus consisted of an electrical heater, a power supply, an electrical multimeter, a thermostatic circulator, a flow meter, a multi-channel data-recorder and a PC. Electrical wires were wound around the evaporator section to supply heat to the heat pipes. The DC power applied to the heater was controlled through a power supply with a variable transformer and measured with a digital multimeter. Both the evaporator and adiabatic sections were thermally insulated to minimize the heat loss to the ambient. The condenser section of the heat pipe was placed in a water-cooling jacket that was connected to a thermostatic circulator. The temperature and the flow rate of the circulator could be adjusted to the desired values. The flow rate was measured by weighing the water mass via a bypass and timing with a stopwatch. Seven calibrated T-type thermocouples were installed along the heat pipe length to measure the surface temperature distributions. Besides, the in- and outlet temperatures of the water-cooling jacket were also measured via thermocouples. The heat transfer rate of the heat pipe was calculated from the measured water flow rate and the temperature difference between the in- and outlet temperatures of the water-cooling jacket. The thermal resistance was calculated from the measured heat transfer rate and the temperature difference between the evaporator and condenser sections. The error estimated was less than $8 \%$ for both the maximum heat transfer rate and the thermal resistance. 

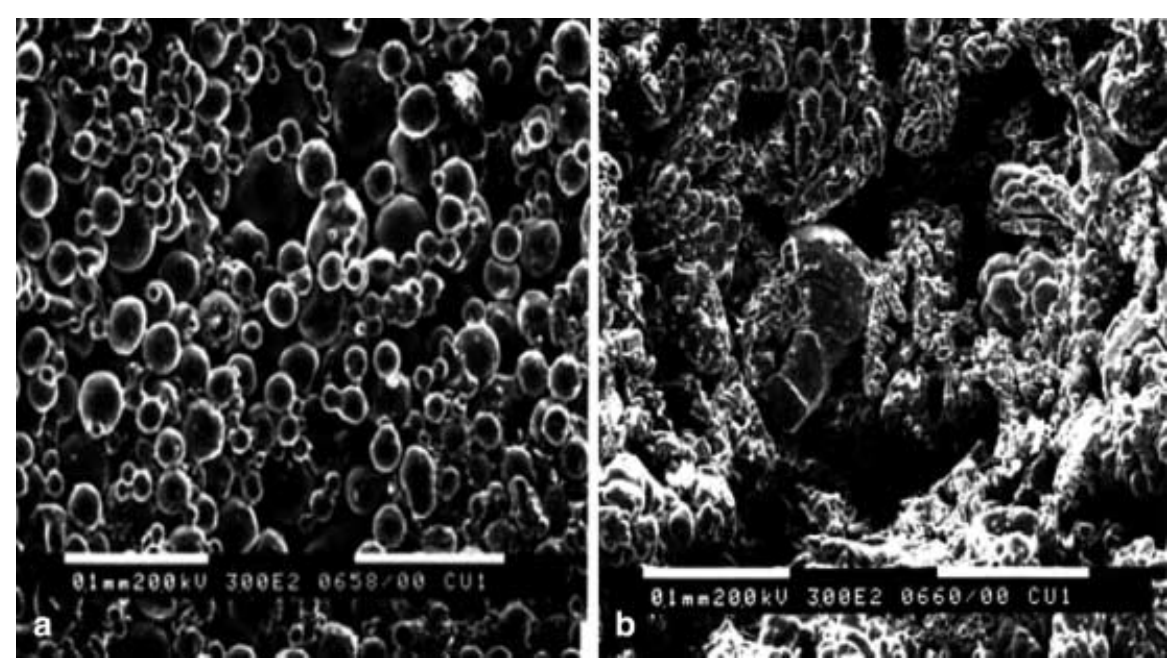

Fig. 5. SEM photograph
3

\section{Results and discussion}

Typical testing results are presented in terms of the temperature distributions along the heat pipe in Fig. 7a. The experiments were conducted at different water coolant temperature. At each cooling temperature, the power input to the heat pipe was gradually increased from a lower level to a higher level until the temperature drop across the heat pipe length reached a higher value. This indicated that dryout might occur at the evaporator section. The abrupt increase in temperature near the end of the evaporator is an example of dryout phenomena. Figure $7 \mathrm{~b}$ shows the thermal performance of heat pipe in terms of temperature difference between evaporator and condenser over heat transfer rate. The slope of the curve in section one is just the effective thermal resistance. The dryout point and the maximum heat transfer rate can also be easily determined via this kind of figure.

\section{Effect of porosity}

As discussed in the previous section, porosity has a profound influence on the maximum heat transfer rate. A $10 \%$ increase in porosity leads to more than a double increase in the maximum heat transfer rate. Before applying special sintering process to increase the porosity, comparison were made between heat pipes with spherical and dendritic copper powders. The other parameters, like mean powder diameter, wick thickness were kept the same. In this experiment, the mean power diameter was fixed around $74 \mu \mathrm{m}$ and the wick thickness was set to be $0.5 \mathrm{~mm}$. The porosities were measured to be 37.1 and $51.6 \%$ for spherical and dendritic copper powder respectively. The spherical powder packed closer than dendritic powder. Their difference can easily be distinguished from the scanning electron microscope pictures, as shown in Fig. 5. The experimental results are shown in Fig. 8. As can be found, the heat transfer rate of the heat pipe with a larger porosity is indeed higher than that with a smaller one. The maximum heat transfer rate of the heat pipe with dendritic powder wick reaches a value over $12 \mathrm{~W}$, while that of the spherical one is only about a half. No obvious difference in the thermal resistance can be found in the tested case here.

\section{Effect of powder diameter}

As discussed in the previous chapter, the mean power diameter is also an important design parameter. Capillary radius of curvature is mainly a function of the mean powder diameter. Porosity is a function of the particle size distribution. The permeability can also be related to the capillary radius of curvature and porosity. This means that the powder diameter is a significant parameter to specify the flow characteristics of the wicks. Figure 9 demonstrates the effect of powder diameter. In this example, the wick thickness is fixed to be $0.5 \mathrm{~mm}$ and the porosity around $36 \%$. The experimental results show that the heat transfer rate of the heat pipe with a larger powder diameter is indeed higher than that with a smaller one. The maxi-

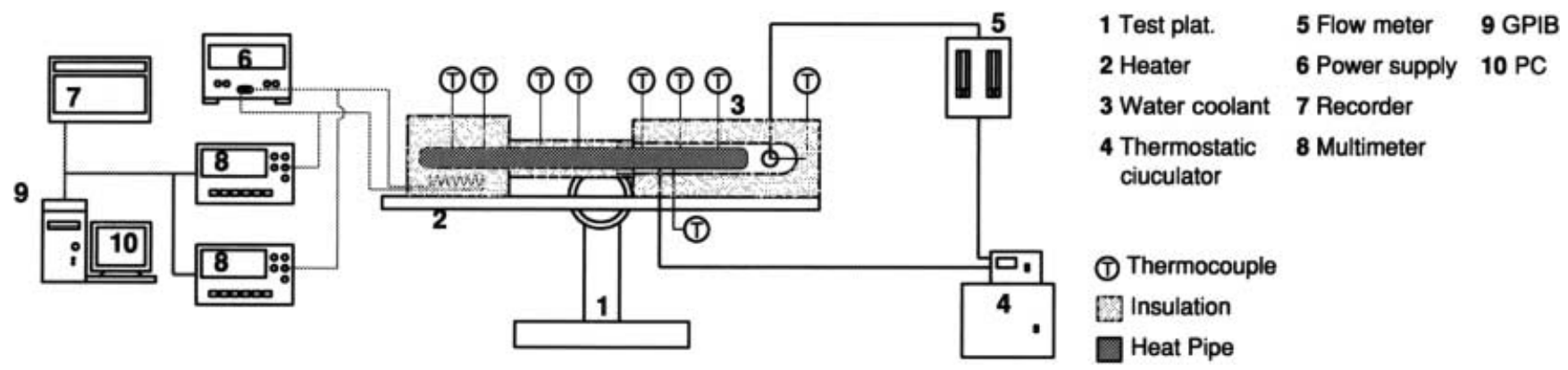

Fig. 6. Testing system 

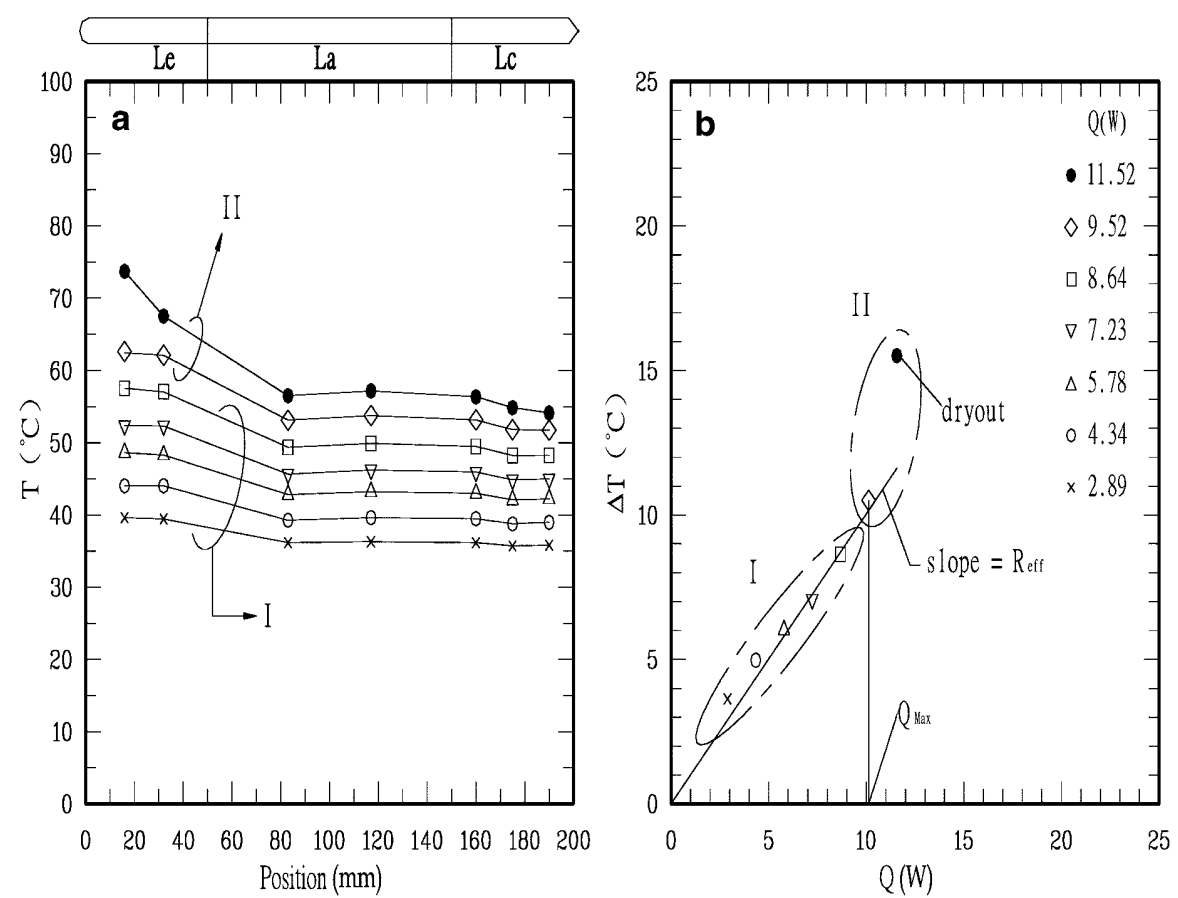

615

Fig. 7. a Temperature distribution along the heat pipe. $\mathbf{b}$ Heat transfer rate as a function of temperature difference mum heat transfer rate of the heat pipe with a mean powder diameter of $95.9 \mu \mathrm{m}$ reaches a value over $13 \mathrm{~W}$, while that with a diameter of $38.9 \mu \mathrm{m}$ is only about $7 \mathrm{~W}$. The measured thermal resistance is around $0.9{ }^{\circ} \mathrm{C} / \mathrm{W}$.

\section{Predictive equations}

Establishing a sound model for prediction of the maximum heat transfer rate necessitates a detailed study of the wick structure parameters. Before that, simple correlation equations were proposed for prediction of the maximum heat transfer rate of sintered miniature heat pipes with dendritic powder. Because there is no available equation

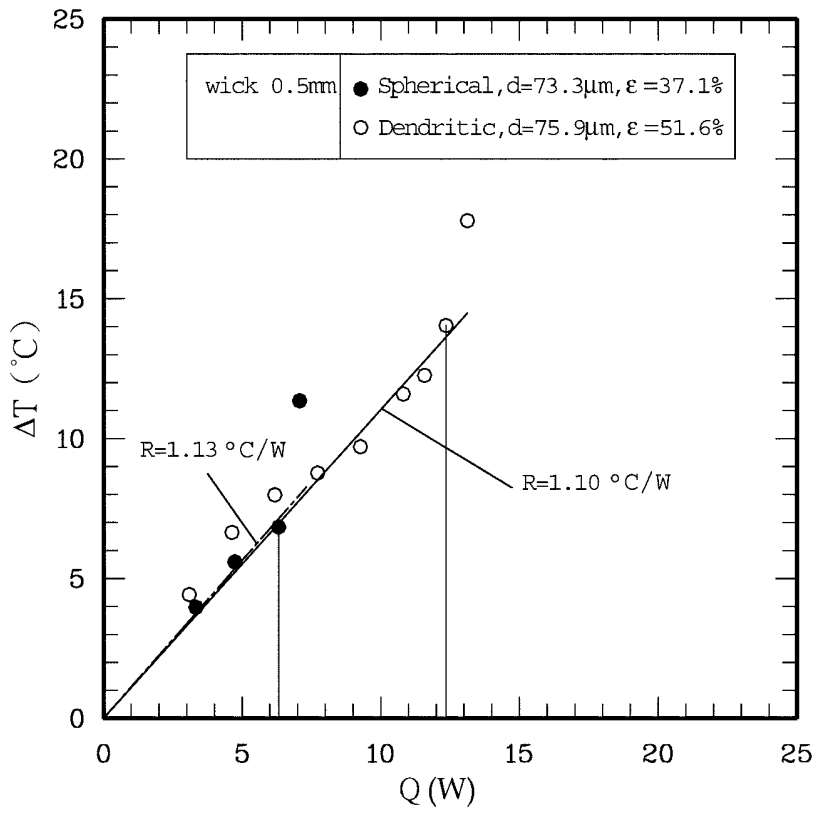

Fig. 8. Effect of porosity on the thermal performance for sintered dendritic powder in the open literature, we tried to compare our experimental results with that calculated from the prediction equations for spherical powder and fiber from Brunswick Co. Handbook (1979) and found that the equations for spherical powder overestimate the maximum heat transfer rate while the equations for fiber underestimate it. By adopting the formulae developed for both sintered spherical powder and fiber and adjusting their proportion (spherical:fiber $=4: 1$ ), the agreement between experimental results and prediction is found to be quite good in the tested operation temperature range. The maximum deviation between them is within $\pm 9 \%$, as shown in Fig. 10 .

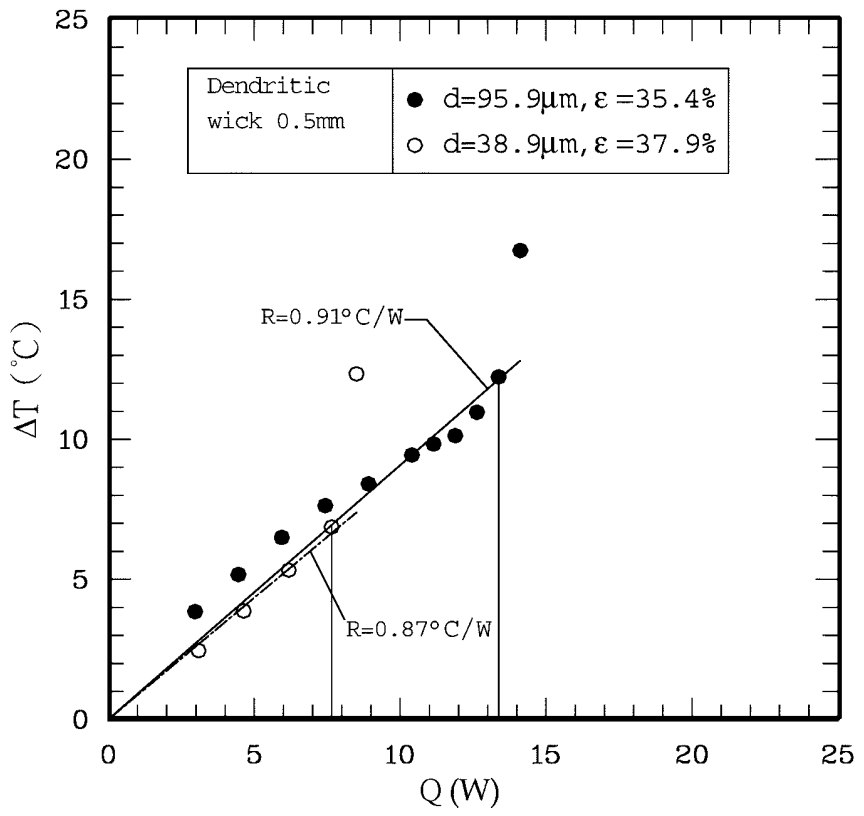

Fig. 9. Effect of powder size on the thermal performance 


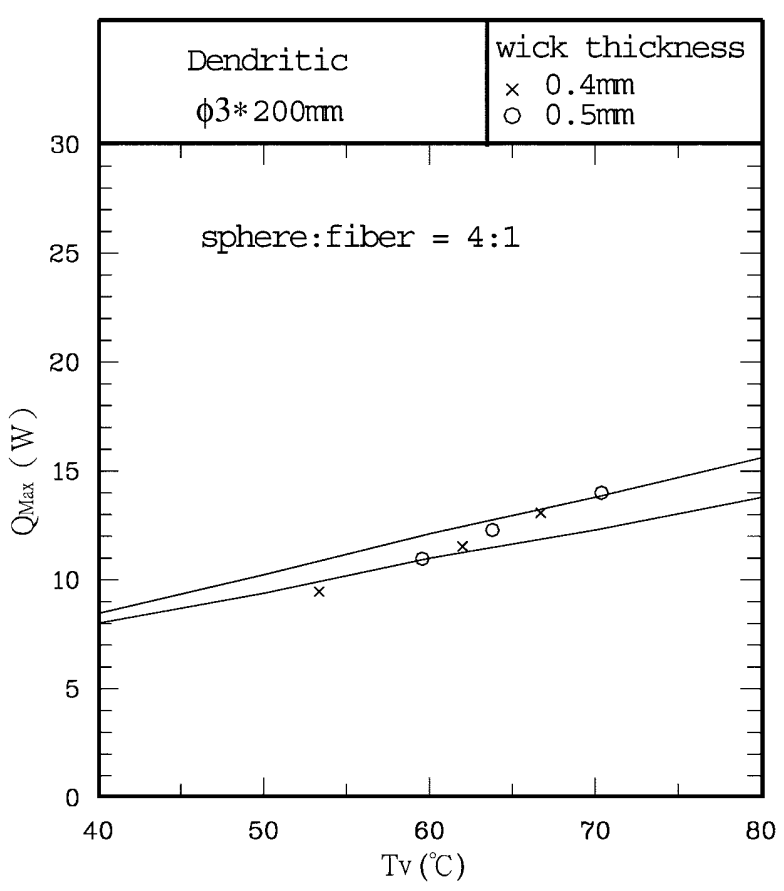

Fig. 10. Comparison between the experimental results and predicted values

\section{4}

\section{Conclusions}

Major conclusions are summarized as follows:

1. The influence of wick structure parameters was determined by using the theory of capillary limitation. The degree of importance is found to be as follows: porosity, powder diameter and thickness of wick structure.

2. Miniature heat pipes with sintered dendritic copper powder wicks were fabricated and tested. The maximum heat transfer rate reaches over $13 \mathrm{~W}$ with an outer diameter of $3 \mathrm{~mm}$ and an effective heat pipe length of $20 \mathrm{~cm}$.

3. Simple correlation equations were proposed for prediction of the maximum heat transfer rate of sintered miniature heat pipes with dendritic powder.

\section{References}

Brunswick Company Handbook, Miami, FL 1979

Cao Y; Gao M; Beam JE; Donovan B (1997) Experiments and analysis of flat miniature heat pipes. AIAA J Thermophys Heat Transfer 11: 158-164

Cao Y; Faghri A; Mahefkey T (1993) Micro/miniature heat pipes and operating limitations. ASME HTD 236: 55-62

Cotter TP (1965) Theory of heat pipes. Los Alamos Scientific Laboratory Report No. LA-3246-MS. The University of California, Los Alamos, NM

Dunn P; Reay DA (1978) Heat Pipes. Pergamon Press, Oxford

Faghri A (1995) Heat Pipe Science and Technology. Taylor and Francis, Washington, DC

Huang WH (2000) Fabrication and performance testing of sintered Miniature Heat Pipe. Master Thesis. National Taiwan University, Taipei, Taiwan

Nguyen T (1998) Advanced cooling system using miniature heat pipes. In: Mobile PC (ed) InterSociety Conference on Thermal Phenomena, Seattle, Washington, DC

Peterson GP (1994) An Introduction to Heat Pipes. Wiley, New York

Peterson GP (1996) Modeling, fabrication, and testing of micro heat pipes: an update. ASME, J Appl Mech Rev 49(10): 75-183 